\title{
Uma suposta contradição na ciência inglesa do século XVII: divulgação $x$ sigilo
}

\section{Ana Maria Alfonso-Goldfarb*}

Resumo: Estudos recentes vêm revisando a composição da literatura que, ao longo do século XVII, serviu como base às ciências em território britânico. Segundo esses estudos, os seiscentistas de fala inglesa dedicaram-se a duas linhagens de texto, originadas em concepçōes de ciência muito distintas. Uma dessas linhagens tinha como fonte principal a antiga "literatura do segredo" que incluía desde velhos e sigilosos manuais de ofício até os milenares e proibidos tratados de hermética, literatura antes reservada a poucos. Diferente dessa, a outra linhagem de textos surgia como um reflexo direto da proposta baconiana para a nova ciência: um saber elaborado por muitos e ao alcance de todos. Exemplos conhecidos dessa linhagem são os livros de divulgação utilizados pelos comenianos ingleses ou mesmo os relatórios, atas e memórias das sociedades científicas, geradores dos primeiros embriões de periódicos dedicados às ciências. Todavia, sob essa aparente contraposição das duas linhagens, há indícios de um profícuo diálogo - expresso sobretudo na correspondência e diários de pensadores da época.

Palavras-chave: ciência moderna - Inglaterra - século XVII - R. Boyle - literatura hermética - J. Wilkins - C. Drebbel - divulgação científica - sigilo - sociedades científicas

\footnotetext{
"Professora do Programa de Estudos Pós-Graduados em História da Ciência da Pontifícia Universidade Católica de São Paulo - PUC-SP.
} 
Porque vasta e minuciosa, ou porque reveladora, a documentação seiscentista inglesa a respeito da "nova ciência" surpreende até hoje. Guerras, pestes e outras catástrofes vividas em território britânico não impediram que ali se registrasse em detalhes e de forma contínua os êxitos, bem como os percalços, das ciências no período ${ }^{(1)}$. Essa imensa coleção de escritos flagraria um momento de transição, revelando questionamentos singulares que, nem sempre óbvios para olhos modernos, acabariam sendo ignorados ou mal entendidos por estudiosos futuros. Na verdade, durante um longo tempo, falou-se muito da ciência inglesa seiscentista, mas em geral privilegiando seu viés moderno e, quase sempre, a partir da leitura indireta ou seletiva de seus escritos. Uma dinâmica não só inglesa e não só aplicada em documentação do Seiscentos que, segundo indicam análises historiográficas contemporâneas, teria gerado boa parte dos mitos até hoje populares sobre a ciência moderna. Por outro lado, também se reconhece atualmente que essa dinâmica formava parte de todo um contexto, jogando um papel significativo no difícil e longo processo de institucionalização da nova ciência ${ }^{(2)}$.

Esse processo de assimilação se daria em solo inglês de forma rápida, mas não menos elaborada do que em outras partes. Panfletos, discursos inflamados, poemas, frases de efeito e peças similares de divulgação, fabricaram ostensivamente, desde o século XVIII, cenas heróicas da nova ciência forjadas a partir de elementos do presente. Eram cenas que, carregadas na coloração local e quase sempre comandadas pela figura de Newton, transformavam a nova ciência num dos grandes orgulhos nacionais. Com base num recorte anacrônico que adere imagens do presente ao passado, aliás típico na época, essa literatura de divulgação, como é óbvio, não precisou de grandes consultas para ser produzida e menos ainda de um escrutínio dos originais seiscentistas. Em todo caso, mais de um século depois, obras de peso elaboradas a partir do contato direto com esses originais, como as de W. Whewell ou de C.R. Weld sobre a Royal Society, continuaram reproduzindo uma história mítica, moderna e vitoriosa da ciência ${ }^{(3)}$. Todavia, quando em 1938 um mapeamento exaustivo da documentação inglesa seiscentista por fim se inicia, na obra que se tornou clássica de R.K. Merton, a perspectiva historiográfica permanece a mesma. Merton 
acreditava que essa massiva produção de escritos - claramente relacionada às formulações de Lorde Bacon - teria sobretudo o propósito de divulgar a então "nova" ciência. De tal sorte que Merton e toda uma escola de estudiosos que se criou em torno dele rastrearam duramente a imensa coleção de relatórios, estudos, diários, protocolos e cartas deixada pelos estudiosos ingleses do século XVII, em busca do modelo de divulgação que teria sido fundamental ao desenvolvimento da ciência nessa época ${ }^{(4)}$.

Esquecendo que essas milhares de páginas eram o produto de um ambiente em que o lombo de mula e o barco a vela se constituíam como os únicos e grandes "órgãos de comunicação", Merton e sua escola de estudos sociológicos confundiram a publicação para intercâmbio com aquela originada a partir do século XIX, dedicada, aí sim, à divulgação ${ }^{(5)}$. Alguns dirão que isto foi um espasmo tardio da visão anacrônica. Outros irão atribuir essa leitura do passado com olhos do presente ao próprio modelo de ciência praticado ainda nas primeiras décadas do século XX (Boas Hall 7). Mas, seja pelo motivo que for, o resultado é que, excluídos da seleta mertoniana ou analisados, ali, fora de contexto, ficaram por exemplo textos preciosos, como a carta de Newton a H. Oldenburg.

Cortês, mas sempre um pouco majestoso, Newton pede a H. Oldenburg, nessa carta sigilosa de 1676, que não divulgue o estudo de Boyle sobre uma estranha fórmula mercurial alquímica. "Muitos", diz ele irônico, "devem estar morrendo de coceira para colocar as mãos nesse conhecimento [...] e sabe-se lá o que não moverão para vê-lo publicado.” E, através de uma série de argumentos bem urdidos, adverte que essa fórmula poderia ser preciosa demais ... ou perigosa demais para cair em domínio público, sem uma longa, refletida e completa avaliação.

Usada repetidas vezes como prova da visão elitista e sectária de Newton, essa carta, porém, guarda indícios talvez menos importantes para a análise de seu caráter do que de sua época. Indícios que emergem, sobretudo, na parte final dessa carta, quando Newton sugere que uma das melhores, se não a melhor, forma de avaliar o curioso estudo de Boyle seria submetê-lo "ao julgamento bem fundamentado de um hermetista sério". Pois considera 
que os filósofos herméticos, como grandes dissimuladores, "sabem muito além do que parece sobre coisas que ninguém mais entende"(6).

Os inúmeros manuscritos alquímicos e herméticos copiados por punho e letra de Newton permitem dizer que sua última sugestão na carta a Oldenburg nada tem de estranho(7) ${ }^{(7)}$, aliás, possivelmente reflete uma inquietude gerada pela crescente publicação desses textos secretos. Uma inquietude, por sinal, compartilhada por vários outros pensadores dessa época. De fato, estudos sobre a história do livro indicam que as pressões de baconianos e comenianos ingleses para que se publicassem textos "úteis", acabaram transformando em best-sellers os chamados "livros de segredo", Ou seja, a afamada explosão editorial do século XVII inglês teve como um de seus fulcros um tipo de literatura supostamente escrita por poucos e para poucos...(8).

Por outro lado, as análises contemporâneas em crítica textual sobre essas obras vêm revelando que as inquietudes de pensadores como Newton tinham fundamento. Nascida em épocas remotas e derivada de fontes templárias que guardavam desde as práticas até a visão de mundo e matéria de culturas antiqüíssimas, a literatura de segredo acumulou durante séculos camadas preciosas de informações. Assim, ao menos em tese, seria possível encontrar nesse tipo de obra a fórmula de um poderoso veneno indiano, ou de um remédio simples para dor de estômago, ou, ainda, um segredo candente de ofício, como o preparo de sais de ouro, além de discussões sobre a escrita de diferentes culturas ou sobre outros sistemas de mundo que não 0 geocêntrico ${ }^{(9)}$.

Mas isso só em tese, porque os autores, ou melhor, os editores dessas obras pretendiam guardar dados sigilosos, e não os revelar. Para tanto, usavam várias formas de cifrar o texto. A mais popular entre eles, talvez por ser a mais complicada, era a do "conhecimento disperso" ${ }^{(10)}$. Conforme 0 próprio nome indica, consistia na fragmentação, dispersão e mistura de trechos da obra que, para voltar a fazer sentido, requeriam um hábil e paciente trabalho de remontagem. Em suma, para extrair informações de um tratado hermético, iatromatemático ou de outros livros de segredo era preciso ser um bom hermeneuta ou, ao menos, um iniciado. Pois, segundo estudos em 
crítica textual, essas eram obras iniciáticas (ou seja, obras pensadas como uma etapa do trabalho entre mestre e discípulo). Seus textos duros e codificados resistiram à febre divulgatória dos séculos XVI e XVII e acabaram provocando o feitio em série de mimeses mal elaboradas que deram origem tanto a ligeiros tratados "faça-você-mesmo" quanto a indigestos livros de ocultismo(11). $^{(11}$.

Não houve, entretanto, em momento algum o risco de se estar "jogando pérolas aos porcos" ao publicar livros de segredo; e aqueles estudiosos que reviravam seus textos sabiam bem disso. Mas também sabiam que a leitura inexperta dessas obras poderia causar perigosos mal-entendidos e até mesmo o descrédito do trabalho de laboratório no qual eram ricas. De tal sorte que o zelo em destrinchar o conteúdo dessas obras antes de divulgá-lo aparece também nas correspondências, diários e cadernos de laboratório de outros estudiosos seiscentistas - embora de forma mais pontual e menos evidente do que na carta de Newton a Oldenburg.

A história que irá sendo contada por esses para-textos é uma história complexa de assimilação e recombinação gradual, mas inexorável, do que antes pertencia à literatura de segredo. Será nessa história de páginas discretas que se encontram os verdadeiros bastidores de alguns debates que, na esfera do público e notório, pareceram ser batalhas travadas entre a razão moderna e o obscurantismo antigo.

Entre esses debates, talvez um dos mais memoráveis seja o travado por Seth Ward e John Wilkins contra John Webster. Os primeiros, ilustres fundadores da futura Royal Society, enquanto o segundo, um defensor de uma reforma insólita no currículo universitário que, entre outras coisas, substituiria disciplinas tradicionais como a lógica por aquelas de cunho observacional-experimental, entre as quais ele sugere alquimia, geomancia, magia operativa... e estudos da cabala. No clamor dessa controvérsia, ocorrida em 1654, Ward e Wilkins, defensores eminentes da nova ciência, acabaram até mesmo usando Aristóteles para atacar Webster. E o fizeram de uma maneira tão primorosa que receberam aplausos dos aristotélicos mais empedernidos. Todavia, o ponto nevrálgico da discussão teria sido o víncu10 traçado por Webster entre as ciências experimentais baconianas e aque- 

las típicas da literatura de segredo. Um vínculo que Ward e Wilkins deixam
claro ser inadmissível:

"Oh! Que celeridade de mudança é a do vento... Oh! Que pouca confiança se pode ter num vilão! Ele, que mesmo agora mantém-se adepto da indução acurada, entrega-se ao caminho místico da $\mathrm{Ca}$ bala. [...] não poderia haver dois caminhos mais opostos no mundo inteiro do que o do Lorde Verulamio e o do Doutor Fludd, um baseado em sólidos experimentos e outro em ideais místicos"(12).

É curioso notar, entretanto, que isto aconteceu enquanto Wilkins e Ward eram professores e membros da Philosophical Society em Oxford. Constam nos anais dessa sociedade, precursora da Royal Society, uma série de cursos oferecidos por um certo Peter Stahl "alquimista experiente alemão" e assistidos por todo o grupo, na mesma época do debate (Gunther 19 , p. 14 e ss.). E no diário de Antony Wood (posteriormente publicado sob 0 título History and antiquities of the University of $O x$ ford), em que recolhe e comenta fragmentos dessas atas de Oxford, consta também que nessa época o seleto círculo da Philosophical Society costumava reunir-se com frequiência:

“[...] na casa de Clerk, um apotecário da paróquia de St. Marie, e ali se exercitavam no preparo de alguns extratos químicos, que desenvolveram e aprimoraram muito antes da restauração, tanto assim que vários desses estudiosos montaram 'elaboratórios' particulares onde praticam em conjunto essas coisas que a memória dos homens não consegue alcançar" (Wood 38, p. 205).

Certamente "essas coisas" não eram remédios para dores de estômago ou cabeça, pois Wood explicita na seqüência que os fundamentos dessas práticas estavam sendo ministrados pelo alquimista Peter Stahl.

Foi Boyle, naturalmente, quem indicou o mestre alquimista ao pequeno círculo de Oxford. Mas é preciso lembrar que Boyle entrara para esse círculo em 1653 graças a uma expressa recomendação de Wilkins. Aliás, em 
sua carta convite (enviada em setembro desse mesmo ano e prontamente aceita por Boyle) Wilkins deixa ver que a inclinação do jovem irlandês para os estudos químicos será o motivo para trazê-lo a Oxford:

"Senhor, se não for prejudicial a vossos afazeres, eu me regozijaria em vos ter na Inglaterra este inverno, sabedor que sou das vantagens de vossa conversação em Oxford, onde vossa presença se tornaria um meio de acelerar e dirigir nossas investigações. Sei que uma pessoa tão bem informada como o senhor, não espera aprender algo entre pedantes [mas] há uma felicidade maior em ensinar do que aprender [...] se eu puder saber de que forma auxiliar em vossas inclinações e vossas necessidades [...] usarei todo meu engenho com esse propósito [...]"(13).

E se despede pondo à disposição de Boyle as melhores acomodações que a universidade oferecia.

Mas as incursões de Wilkins nas artes secretas do laboratório não começaram aí. Um ano antes vai a Londres exclusivamente para fazer uma visita reservada a Elias Ashmole, editor do Theatrum chemicum Britannicum $^{(14)}$, a maior coletânea de tratados alquímicos da Inglaterra seiscentista. Cuidadosamente registrada em 14 de junho de 1652 no diário particular de Ashmole, essa visita teria acontecido para tratar de assuntos e estudos que naturalmente interessavam aos dois (Josten 22, p. 615). Ashmole acabara de publicar sua monumental coletânea hermética, repleta de obras antigas e clássicas, nas quais, certamente, Wilkins tinha interesse.

Havia pouco, Wilkins tinha dedicado, em seu Mathematical magick, alguns capítulos ao moto perpetuo gerado por artes químicas (ou alquímicas). Nesses breves mas densos capítulos, esse suposto mecanicista ${ }^{(15)}$ de quatro costados contraria quase tudo que dissera no resto da obra. Sempre alegando fazer meras especulações, percorre um espectro variadíssimo de livros de segredo, apresenta uma visão de matéria não corpuscular; mostra sua preferência por tratados de hermética antiga, mesmo dizendo não entendê-los; e, embora critique os alquimistas recentes, acaba adotando suges- 
tões como o fulminato de ouro ou uma estranha "quintessência" que reno. vava o ar, oferecidas por Cornelio Drebbel - um seiscentista holandês que esteve a serviço da Coroa inglesa ${ }^{(16)}$. Não é de se admirar, portanto, que com essas "especulações" em sua bagagem Wilkins tenha percorrido meio mundo à cata de esclarecimentos, como de resto boa parte de seu círculo de estudiosos.

Enquanto o De natura elementorum e o De quinta essentia ${ }^{(17)}$ de Cornelio Drebbel circulavam com desenvoltura pelo território britânico, os segredos do movimento perpétuo sugeridos por ele eram duramente investigados pelo grupo que gerou a Royal Society. Conforme visto antes, um desses segredos seria uma fórmula para a constante renovação do ar, usada por Drebbel numa espécie de submariño que teria chegado ao fundo do Tâmisa.

Como Drebbel morreu em 1633 e o seu segredo continuava bem escondido em meio ao texto, vemos o círculo de estudiosos ingleses tentando obter informações sobre o trabalho de Joachim Becher, alquimista germânico que se dizia conhecedor dessa mesma fórmula. Assim, em carta de Oldenburg a Samuel Hartlib de outubro de 1658, o tema volta a surgir:

"O mesmo homem de artes [J.J. Becher] falou-me de outra invenção sua a que chama nova argonáutica, através da qual barcos de guerra podem ser construídos com baixos custos e consertados com brevidade, e são indestrutíveis, podendo ancorar sobre ou sob as águas. [...] vi seus manuscritos [...] e ele me assegurou que pode fazer esses barcos e demonstrá-los e que seu conhecimento não é meramente ideal e impraticável [...]"(18).

Três cartas foram trocadas entre os dois, e como Hartlib, homem de muitas conexões, não dera uma resposta conclusiva, Oldenburg escreve a Becher diretamente, em março de 59: "[...] no que concerne a vossa invenção argonáutica, todos que refletiram sobre ela estão espantados e seria urgente que fosse posta em prática [...]" (Oldenburg 28, Vol. 1, p. 209, carta de 12 de março de 1658/9). Muitas cartas e averiguações depois, numa cor- 
respondência de Becher a Oldenburg, em setembro de 1660, percebe-se que os esforços do grupo inglês foram vãos:

"A razão para não ter escrito antes são meus achaques tradicionais. Meus trabalhos de química deverão sair brevemente num catálogo de Frankfurt e além disso fiz novas descobertas, até agora desconhecidas por outros, coisas sobre a simpatia magnética (etc., etc....) devo completar minha máquina de movimento perpétuo em pouco tempo. Se algum mecenas proporcionar os meios, talvez eu a divulgue [...]" (Oldenburg 28, Vol. 1, p. 393, carta de 17 de setembro de 1660).

Diante de tantas delongas e evasivas, a saída foi voltar ao texto de Drebbel. E, como nesse caso tratava-se de um livro de segredo, parece que quem pôs mãos à obra foi R. Boyle. Numa carta a seu sobrinho Lorde Dungarvin, nesse mesmo ano, Boyle fala de seus esforços nessa direção:

"[...] Cornelio Drebbel, que entre outras coisas estranhas teria construído um barco para o Rei James que andava embaixo d'água (etc., etc.). Estou mencionando essa história porque ouvi de seu genro que seria possível fazê-lo, sem que as pessoas sufocassem, por longos períodos e sem nenhuma outra inconveniência. Parece que isso dependia de uma certa quintessência que Drebbel imaginava não fosse o corpo inteiro do ar. Só essa espirituosidade (como dizem algum químicos) serviria na verdade à respiração, que uma vez gasta deixaria restos ou uma espécie de carcaça que não serviria nem mesmo para reavivar a chama vital do fogo; assim, além do equipamento do barco, Drebbel inventou também uma espécie de líquido químico, que na verdade era o principal segredo dessa navegação. Pois quando de tempo em tempo ele percebia que a parte leve e pura do ar era consumida, ou saturada por respiração e fumaças de barco, ele abria um dos tonéis cheios desse líquido, restaurando ao ar suas partes vitais, fosse por dissipação ou precipitação 
das exalações grosseiras, ou por outra forma ininteligível que agora tratarei de examinar, passando a fazer disso o meu trabalho a partir daqui [...]" (New experiments physico-mechanical, touching the spring of the air. In: Boyle 8, Vol. 1, p. 69-70).

Não é preciso dizer que, uma vez fundada a Royal Society, uma das comissões lideradas por Boyle dedicou anos a esse estudo. Mas, em 1667, numa das reuniões plenárias, ainda sem o resultado que gostaria, Boyle volta a questionar o estranho caso de Drebbel:

"Dando ocasião a um debate sobre qual seria essa qualidade do ar que o torna próprio à respiração. Alguns pensam que se torna irrespirável porque a ele se aderem e misturam vapores grosseiros. O senhor Hooke tem a opinião de que existe uma espécie de qualidade nitrosa no ar [...] que se for gasta ou misturada torna 0 ar irrespirável"(19).

Uma vez que Boyle e Hooke tinham a mesma opinião, durante anos tentaram obter esse "princípio respirável" a partir do salitre. Eventualmente, esse trabalho febril que começou num livro de segredo, desembocaria nas investigações posteriores dos pneumaticistas ingleses. Mas essa é uma outra história de uma outra correspondência e de uma época em que a ciência moderna já era soberana.

No século XVII, porém, a relação entre os textos públicos e o textos reservados ainda tem muita história para contar. Porque, em última análise, mesmo aqueles para-textos recolhidos por Oldenburg e publicados sob a forma de periódicos (Transactions of the Royal Society) tiveram por objetivo "juntar a opinião de todos os sábios"(20), e não exatamente divulgá-la. Ou, ao menos, não da forma que o faria a imprensa no século XIX, nem nas pro-" porções alcançadas por "livros de segredo" ou tratados "faça-você-mesmo", ainda no século XVII ${ }^{(21)}$. 
Abstract: New studies making a review of the literature's composition that at the XVII ${ }^{\text {th }}$ century is served as ground to the sciences in British territory. According to these studies, in this century the English speaker men are consecrated to two lineages of text which has its origin from much different conceptions of science. One of these lineages has as primary source the ancient "secret literature" which includes since old and secret office workship manuals till the milenary and forbbiden hermetic treatises, which are before reserved to few. Different from it, the other lineage of texts rise as a direct reflex of the Baconian project to a new science: one knowledge elaborated by a great deal and at the reach of all. Knowing examples of this lineage are the divulgation books used by the English Comenians or even the reports, proceedings and memories of the scientific societies which generated the first embryos of the exclusively devoted to the sciences periodicals. However, under this apparent opposition of the both lineages, there are indications of a proficuous dialog - expressed above all in the correspondence and diaries of the thinkers of time.

Key-words: modern science - England - XVII th century - R. Boyle - hermetic and secret literature - J. Wilkins - C. Drebbel - scientific divulgation - scientific societies

\section{Notas}

(1) Conforme poderá ser notado adiante, existe uma atividade significativa em torno da ciência, registrada no meio do século XVII, período de grande instabilidade em território britânico. Assimilando a proposta baconiana de constante intercâmbio e estudo entre os amantes das ciências, essa longa série de trabalhos e registros foi sendo elaborada sem interrupções, sobretudo nos anos 40, apesar dos períodos de guerra civil e outras guerras, das mudanças radicais no governo e de vários surtos de peste; vide, por exemplo, M. Purver, primeiro a publicar um estudo moderno analisando a rede de intercâmbios e a expressiva documentação que antecedem elou de alguma forma estiveram envolvidos com as origens da Royal Society, ou seja,
com o foco central da produção britânica em ciência do Seiscentos (Purver 29). 
(2) Sobre a revisão historiográfica que vem se dando há mais de quatro dé. cadas, ver a coleção de estudos organizada por A. Thackray (Thackray 33). A. Debus, um dos iniciadores dessa revisão, tem publicado uma série de tra. balhos enfocando o histórico processo e oferecendo algumas perspectivas futuras (Debus 12). Sobre o longo e difícil caminho institucional da ciência moderna, entre os séculos XVII e XIX, evidente sobretudo no caso de uma, então, ciência "nova" como a química, vide, por exemplo, a coleção de es. tudos organizada por A. Donovan, em particular o estudo do próprio Do. novan (Donovan 14, p. 214-31); ou ainda o artigo de H.-G. Schneider (Schneider 30).

(3) Para referências à complexa elaboração da literatura que divulgou a nova ciência no século XVIII - em que aparecem figuras como Alexandre Pope, que, embora reticente sobre o tipo de ciência praticado por Newton, cria sob encomenda um dos poemas que imortalizaram esse homem da ciência mesmo entre aqueles que não tinham lido uma página de sua obra-, vide, por exemplo, os ensaios de D. Gjertsen e G. Cantor na coleção orga. nizada por J. Fauvel et al. (Fauvel et al. 18). Para as obras tanto históricas quanto filosóficas sobre a ciência escritas por W. Whewell (Whewell 36), vide também a obra de C.R. Weld (Weld 35).

(4) A obra inicial de R. Merton tornou-se um clássico da sociologia da ciência (Merton 24). Vide também o artigo de R. Merton e H. Zuckerman (Merton \& Zuckerman 26), como ainda o desenvolvimento posterior do seu trabalho (Merton 25).

(5) Para críticas ao modelo mertoniano, vide S. Shapin (Shapin 31).

(6) Ambos os trechos provêm da mesma carta, datada de 26 de abril de 1676, e enviada secretamente (Newton 27, Vol. 2, p. 1-3).

(7) Dobbs 13, em especial os capítulos 4 e 5 e apêndices $A, B$ e $C$.

(8) Vide, por exemplo, E. Eisenstein, em especial o Cap. 6 (Eisenstein 17): vide também R.B. Barnes (Barnes 6), e W. Eamon (Eamon 16), caps. 9 e 10. Sobre o tipo de literatura mais comum nas prateleiras desde o século XV. vide L. Hallewell (Hallewell 20). Vide também em particular, no caso inglês. S.L. Hindman (Hindman 21), em especial o Cap. 7. 
(9) Sobre a literatura de segredo, vide novamente Eamon (Eamon 16), em uspecial a parte 1, Cap. 1; vide também introdução de B.P. Copenhaver (Copenhaver 9); e A.M. Alfonso-Goldfarb (Alfonso-Goldfarb 3), em especial o Cap. 5.

(10) Sobre a concepção de conhecimento disperso atribuído por Jabir a Platão, vide por exemplo os trabalhos de H.E. Stapleton (Stapleton 32) $e$ de P. Kraus (Kraus 23, p. 49).

(11) Sobre isso, vide os trabalhos de Eamon (Eamon 16, p. 91 e ss.) e de A.M. Alfonso-Goldfarb (Alfonso-Goldfarb 4) (no prelo).

(12) J. Wilkins \& S. Ward, Vindiciae academiarum, Oxford, L. Lichfield, 1654, p. 46, ed. fac-similar (Debus 11); vide também os comentários do organizador no Cap. 4.

(13) Espólio dos papéis de Wilkins, citação literal em Gunther (Gunther 19, p. 11).

(14) Ed. fac-similar do Theatrum chemicum Britannicum, da edição de Londres, 1652 (Ashmole 5).

(15) Sobre a dúbia faceta mecanicista de Wilkins, permita-me remeter a A.M. Alfonso-Goldfarb (Alfonso-Goldfarb 1), em especial os caps. 2 e 7.

(16) J. Wilkins, Mathematical magick, ed. fac-similar da $2^{\underline{a}}$ ed., Londres, 1802. In: Wilkins 37, em especial os caps. 9-12; cf. ainda artigo de A.M. Alfonso-Goldfarb (Alfonso-Goldfarb 2).

(17) Ambas as obras se encontram em Drebbel 15.

(18) $\mathrm{H}$. Oldenburg em sua carta de 18 de outubro de 1658 (Oldenburg 28 , Vol. 1, p. 187).

(19) O debate que no caso faz parte da atas internas da Royal Society, não publicadas, é literalmente citado num estudo sobre Drebbel de G. Tierie 1067 34, p. 67), referente à reunião na Royal Society de 16 de junho de 
(20) H. Oldenburg em carta a M. Malpighi, de 25 de março de 1669 (0l. denburg 28, Vol. 5); vide também o comentário sobre essa carta por E. Eisenstein (Eisenstein 17, p. 695).

(21) Sobre a relação entre publicação e divulgação dentro de comunidades científicas contemporâneas, vide, por exemplo, Crane 10. E sobre a difusão dos livros de segredo e dos tratados "faça-você-mesmo" no século XVII, vide novamente Eamon 16, caps. 7 e 10.

\section{Referências Bibliográficas}

1. ALFONSO-GOLDFARB, A.M. A magia das máquinas. John Wilkins e a origem da mecânica moderna. São Paulo, Experimento, 1994.

2.___ "An 'older' view about matter in John Wilkins 'modern' Mathema. tical magick”. In: DEBUS, A.G. \& WALTON, M.T. (orgs.). Reading the book of nature. Kirksville, Thomas Jefferson University Press, 1998, p. 133-47.

3. Livro do tesouro de Alexandre. Trad. de S. Jubran e A.M. AlfonsoGoldfarb. Petrópolis, Vozes, 1999.

4. centuries". In: WILLIAMS, G. \& GUNNOE, C. (orgs.). Sixteenth century essays and studies (no prelo).

5. ASHMOLE, E. Theatrum chemicum britannicum. Debus, A.G. (org.). Nova York/Londres, Johnson Reprint Corporation, 1967.

6. BARNES, R.B. "Astrology and popular print in Germany". In: BARNES, R.B. (org.). Books have their own destiny. Kirksville, Thomas Jefferson University Press, 1998 (Sixteenth Century Essays \& Studies, Vol. L). 
7. BOAS HALL, M. "The Royal Society's role the diffusion of information in the seventeenth century". In: Notes \& Records of the Royal Society, Vol. 29, n⿳⺈ 1, 1975, p. 173-203.

8. BOYLE, R. The works of the honourable Robert Boyle. Ed. por T. Birch. Londres, 1772, 6 vols.

9. COPENHAVER, B.P. (org./est.). Hermetica. Cambridge, Cambridge University Press, 1992.

10. CRANE, D. Invisible colleges. Chicago/Londres, University of Chicago Press, 1972.

11. DEBUS, A.G. Science and education in the seventeenth century. Londres/ Nova York, Macdonald and Elsevier, 1970.

12. "Chemists, physicians, and changing perspectives on the scientific revolution”. In: Isis, Vol. 89, n 1, 1998, p. 66-81.

13. DOBBS, T. The foundations of Newton's alchemy. Reimpressão: Cambridge/Nova York, Cambridge University Press, 1984.

14. DONOVAN, A. (org.). The chemical revolution: essays in reinterpretation. In: Osiris, Vol. 4, 1988.

15. DREBBEL, C. Epistola ad Sapientissimum Britanniea Monarcham Iacobum. Genebra, Tournes, 1628.

16. EAMON, W. Science and the secrets of nature. Princeton (N.J.), Princeton University Press, 1994.

17. EISENSTEIN, E. The printing press as an agent of change. Vol. 2. Cambridge, Cambridge University Press, 1979.

18. FAUVEL, J. et al. (org.). Let Newton be! Oxford/Nova York, Oxford University Press, 1988.

19. GUNTHER, R.T. Early science in Oxford. Oxford, Printed Subscribers, 1923. 
20. HALLEWELL, L. "Livros e leitura na América Hispânica". In: BESSONE T. \& QUEIROZ, T. (orgs.). América Latina: imagens, imaginação e imaginário. São Paulo/Rio de Janeiro, Expressão e Cultura/Edusp. 1997.

21. HINDMAN, S.L. Printing the written word. Ithaca/Londres, Cornell University Press, 1991.

22. JOSTEN, C.H. (org.). Elias Ashmole: his autobiographical and historical notes. Oxford, Clarendon Press, 1966.

23. KRAUS, P. Jabir ibn Hayan. Reimpressão: Paris, Les Belles Lettres, 1986.

24. MERTON, R. "Science, technology and society in seventeenth-century England”. In: Osiris (1ª́rie), 4, 1938, p. 360-632.

25. The sociology of science. Chicago/Londres, University of Chicago Press, 1973.

26. MERTON, R. \& ZUCKERMAN, H. "Patterns of evaluation in science". In: Minerva, Vol. 9, 1971, p. 66-100.

27. NEWTON, I. The correspondence of Isaac Newton. Ed. por H.W. Turnbull et al. Cambridge, Publicação da Royal Society na Imprensa Universitária, 1959-77.

28. OLDENBURG, H. The correspondence of Henry Oldenburg. Org. e trad. de A.R. Hall and M.B. Hall. Madison, University of Wisconsin Press, 1965.

29. PURVER, M. The Royal Society: concept and creation. Londres, Routledge \& Kegan Paul, 1967.

30. SCHNEIDER, H.-G. "The fatherland of chemistry". In: Ambix, Vol. 36, $\mathrm{n}^{\circ}$ 1, 1989, p. 14-21.

31. SHAPIN, S. "History of science and its sociological reconstrution". In: History of Science, Vol. 20, 1982, p. 157-211. 
32. STAPLETON, H.E. "The antiquity of alchemy". In: Ambix, Vol. 5, ne 1-2, 1953, p. 1-43.

33. THACKRAY, A. (org.) "Construting knowledge in the history of science". In: Osiris, Vol. 10, 1995.

34. TIERIE, G. Cornelis Drebbel. Amsterdã, H.J. Paris, 1932.

35. WELD, C.R. History of the Royal Society: compiled from authentic documents. Londres, J.W. Parker \& W. Strand, 1848, 2 vols.

36. WHEWELL, W. Selected writings. Org. por Y. Elkana. Chicago, University of Chicago Press, 1984.

37. WILKINS, J. Mathematical magick. Ed. facsimilar da 2 $2^{\mathrm{a}}$ ed., Londres, 1802. In: The mathematical and philosophical works of J. Wilkins. Londres, Franck Cass, 1970.

38. WOOD, A. The life and times of Antony Wood, antiquary. Org. por A. Clark. Oxford, Oxford University Press, 1900. 